\title{
Kinetic Study on Flooded Soil Recovery Using Soil Containing Arbuscular Mycorrhizal Fungi
}

\author{
N. Zainol ${ }^{1, *}, N$. Thangaperumal, N.H. Zahari and N.H. Aziz \\ ${ }^{1}$ Faculty of Chemical \& Natural Resources Engineering, Universiti Malaysia Pahang, 26300 Gambang, \\ Pahang, MALAYSIA.
}

\begin{abstract}
The purpose of this research was to determine the kinetic parameters for flooded soil recovery via soil containing Arbuscular Mycorrhizal fungi (AMF). The general procedures of this experiment started by preparation of simulated flooded soil (FS) and soil containing AMF (SA). Mixed soil was prepared by mixing FS and SA with ratio 1:1. Onion plant was chosen as a host plant and planted in the mixed soil for 14 days. The plantation was conducted in ambient temperature. The nutrients (nitrogen, phosphorus and potassium) concentrations in the soil were tested using HACH Spectrophotomer. The Michaelis-Menten equation was used to study the nutrients recovery in soil. The Lineweaver-Bulk plot was used to solve the Michaelis-Menten equation. From the experiment conducted, the maximum nutrient uptake (Vmax) and bonding affinity $(\mathrm{Km})$ obtained for nitrogen $(\mathrm{N})$ were $6.28 \mathrm{mg} / \mathrm{l} . \mathrm{d}$ and $82.17 \mathrm{mg} / \mathrm{l}$, for phosphorus $(\mathrm{P})$ were $9.80 \mathrm{mg} / \mathrm{l} . \mathrm{d}$ and $60.96 \mathrm{mg} / \mathrm{l} . \mathrm{d}$ and for potassium $(\mathrm{K})$ were $0.07 \mathrm{mg} / \mathrm{l} . \mathrm{d}$ and $4.55 \mathrm{mg} / \mathrm{l}$. By comparing the result with other researcher, it showed that the Vmax and $\mathrm{Km}$ of nitrogen $(\mathrm{N})$ and phosphorus $(\mathrm{P})$ obtained were higher than other research. This was because the onion required a high level of $\mathrm{N}$ and $\mathrm{P}$ in the soil compared to other host plant.
\end{abstract}

\section{Introduction}

Flood has many direct impacts especially the deposition of sand and debris on productive lands, erosion of agricultural soils, anaerobic condition and this phenomenon called fallow soil syndrome. There was concern that crop production problems would develop when subsequent crops were planted to previously flooded areas. One of symptoms of flooded soil syndrome is phosphorus deficiencies developing in crops even when adequate soil phosphorus concentrations are measured. When the soil was flooded, the nutrients in the soil leached and removed out from the soil profile. Though, most of the farmers used chemical method such as fertilizer to germinate the soil nutrients back. However, this method brings more harm than good. The excess fertilizer ends up moving downwards to

\footnotetext{
*Corresponding author: azwinaz@gmail.com
} 
the soil and lead to contamination of drinking water supplies and eutrophication of water bodies [1]. Therefore, the biological method was used to recover back all the nutrients inside the soil via Arbuscular Mycorrhizal fungi (AMF). According to [2], AMF has the ability to maintain the structure of soil and catching the nutrients from leaching out from the soil by binding it to the host plant's root. AMF is the most common type of fungus root that occurs in most soils [3]. However, AMF needs a host plant for them to survive well in the soil. They cannot propagate well in soil alone. According to Smith and Read [3], the host plants provide all the organic carbon $(\mathrm{C})$ requirements of the fungi, so that AMF symbioses are mutualistic, based on an exchange of plant $\mathrm{C}$ for soil phosphorus $(\mathrm{P})$ and other nutrients such as nitrogen $(\mathrm{N})$, potassium $(\mathrm{K})$, calcium $(\mathrm{Ca})$ and others. It can be concluded that the symbiotic relationship between the AMF and host plant occurred when the fungi receives food carbohydrates from the plant and the plant will receive nutrients especially phosphorus from the AMF. Hence in this study the best method to recover flooded soil was via AMF by helped from the host plant. To fully understand the kinetic reactions of nutrients uptake by AMF, the Michaelis-Menten equation was used. In microbial competition theory, the Michaelis-Menten equation is used to examine the relationship between the rate of nutrients uptake and AMF. The kinetic parameters Vmax and $\mathrm{Km}$ determined the maximum of nutrients uptake by AMF and the bonding affinity between the AMF and the nutrients. This kinetic reaction also can be used to design equation for rate law and also used to scale up the operation. Therefore, the main objectives of this study were to use SA to recover the flooded soil and determine the kinetic parameters of nutrients uptake by AMF.

\section{Materials and Methods}

\subsection{Experimental set-up}

The soil containing AMF (SA) was collected from the domestic vegetable garden and kept in the ambient temperature at Universiti Malaysia Pahang laboratory. Then, simulated flooded soil (FS) was prepared by submerging the agriculture soil in the water for two weeks. A $200 \mathrm{~g}$ of mixed soil was prepared by mixing the SA and the FS according to the ratio of 1:1. Onion plant (Allium cepa L.) was selected as a host plant in this study. Onions were bought from the convenient store. The onion was planted from the bulb using mixed soil in 14 pots. These 14 pots represented 14 days of reaction time for FS recovery. The plantation was conducted in the ambient temperature and atmospheric pressure. The sample of soil was collected daily ( 24 hours), then, the sample was kept in $-20^{\circ} \mathrm{C}$ freezer to stop the activity of fungi in the soil and to avoid the denaturation of the soil contents [4].

\subsection{Kinetic study}

In order to study the kinetic of nutrients uptake by AMF, the Michaelis-Menten equation was used [5].

$$
\mathrm{v}=\frac{\operatorname{Vmax} S}{\mathrm{Km}+S}
$$

Where $\mathrm{v}$ is the rate of nutrient uptake, Vmax is a maximum rate achieved by AMF and [S] is the concentration of nitrogen $(\mathrm{N})$, phosphorus $(\mathrm{P})$ or potassium $(\mathrm{K}), \mathrm{Km}$ is the bonding affinity between the AMF and which the reaction rates half of the Vmax and $[S]$ is the 
initial nutrient concentration. In order to solve the above equation, the Michaelis-Menten equation was arranged linearly as shown below.

$$
\frac{1}{\mathrm{~V}}=\frac{\mathrm{Km}}{\mathrm{Vmax}}\left[\frac{1}{S}\right]+\frac{1}{\mathrm{Vmax}}
$$

According to Lineweaver-Bulk plot, the $1 / \mathrm{V}$ against $1 / \mathrm{S}$ was plotted. From the graph, the value of Vmax and $\mathrm{Km}$ were obtained. The 1/Vmax value obtained from y-intercept while $\frac{\mathrm{Km}}{\mathrm{Vmax}}$ from the gradient of graph. From the calculation, the Km and Vmax determined the rates of $\mathrm{N}, \mathrm{P}$, and $\mathrm{K}$ uptake by $\mathrm{AMF}$.

\subsection{Sample Analysis}

Soil sample near the onion plant roots was analyzed for the N, P, K concentrations by using $\mathrm{HACH}$ Spectrophotometer. In order to test potassium content, Potassium 1, 2, 3 reagent powder pillows were used as a reagent by using tetraphenylborate method (Method 8049). Potassium in the sample reacts with sodium tetraphenylborate to form an insoluble white solid. The amount of turbidity produced is proportional to the potassium concentration. Nitrogen was analysed using persulfate digestion method (Method 10071). An alkaline persulfate digestion converts all form of nitrogen to nitrate. Sodium metabisulfite is added after the digestion to eliminate halogen oxide interferences. Nitrate then reacts with chromotropic acid under strongly acidic conditions to form yellow complex. The measurement wavelength is $420 \mathrm{~nm}$ for spectrophotometer. For the phosphorus concentration, the potassium persulfate powder pillow was used with sodium hydroxide as a standard solution (Method 10127). Phosphate that present in organic and condensed inorganic forms must be converted to reactive orthophosphate before analysis. Organic phosphates were converted to orthophosphate by heating with acid and persulfate. Orthophospate reacts with molybdate in an acid medium to produce a phosphomolybdate complex. In the presence of vanadium, yellow vanadomolybdophosphoric acid forms. The intensity of the yellow colour is proportional to the phosphate concentration.

\section{Results and Discussion}

\subsection{Nutrients Profile}

The concentrations of nutrients $(\mathrm{N}, \mathrm{P}$ and $\mathrm{K})$ in mixed soil (FS+SA) started to increase throughout the growing stages of onion plant. Based on Figure 1, on second day the nitrogen concentration started to increase gradually until the day 11. This stage was known as the growth stage. According to research by Feldman [2], the AMF has the ability to maintain the structure of soil and catching the nitrogen from leaching out from the soil. Therefore, the nitrogen content in the soil keeps increasing. As the height of host plant increased, the nitrogen content in the soil also increased. This was probably due to the release of nutrients by AMF during the growth of host plant [6]. The AMF started to bind with the host plant's root and triggered the accumulation of nitrogen in the soil. However, it started to decrease starting from day 12 till day 14. This happened because the AMF consumed the nitrogen and converted it into protein and supply to the host plant as food nutrients. AMF in the soil has the ability to increase nitrogen in the soil through decomposition of organic matter [2]. They also can decrease the amount of nitrogen in the soil by consuming it and convert it into protein. The presence of AMF was known to increase proportional to the availability of nutrients in soil [7-9]. 
While for the potassium $(\mathrm{K})$, the concentration profile also has quite the same trends as $\mathrm{N}$ profile. According to Jeff [10], $\mathrm{K}$ is immobile in the soil, meaning they don't move readily with water. Therefore, the $\mathrm{K}$ concentration was increasing because the AMF in the soil more tightly bind with nutrient. However, at day 13, the K content started to decrease. This is because the AMF started to supply the potassium in the soil to the host (onion plant).

The phosphorus $(\mathrm{P})$ concentration in the soil (Figure 1) also showed the same increasing pattern but in a fluctuated trend. This is because arbuscules in the AMF symbiosis undergo a cycle of growth, degradation, senescence and recurrent growth [10]. Phosphorus is extremely immobile in the soil and is likely to stay wherever it is placed unless moved by erosion or crop export [10] High soil P levels have been found to be detrimental for the symbiotic association of AMF with plants. These fungi need the root exudates to their vegetative growth. AMF symbioses can increase the spatial availability of $P$, extending the nutrient absorptive surface by formation of mycorrhizal hyphae. In the symbioses, nutrients are transferred by AMF via their extensive mycorrhizal mycelium to plants while in return the fungi receive carbon from the plant. AMF not only influence plant growth through increased uptake of nutrients (e.g. P, N, and K), but may also has non-nutritional effects in terms of stabilization of soil aggregates and alleviation of plant stresses caused by biotic and abiotic factors [3]. Overall, it can be concluded that, the AMF can increase the nutrients content in the flooded soil.

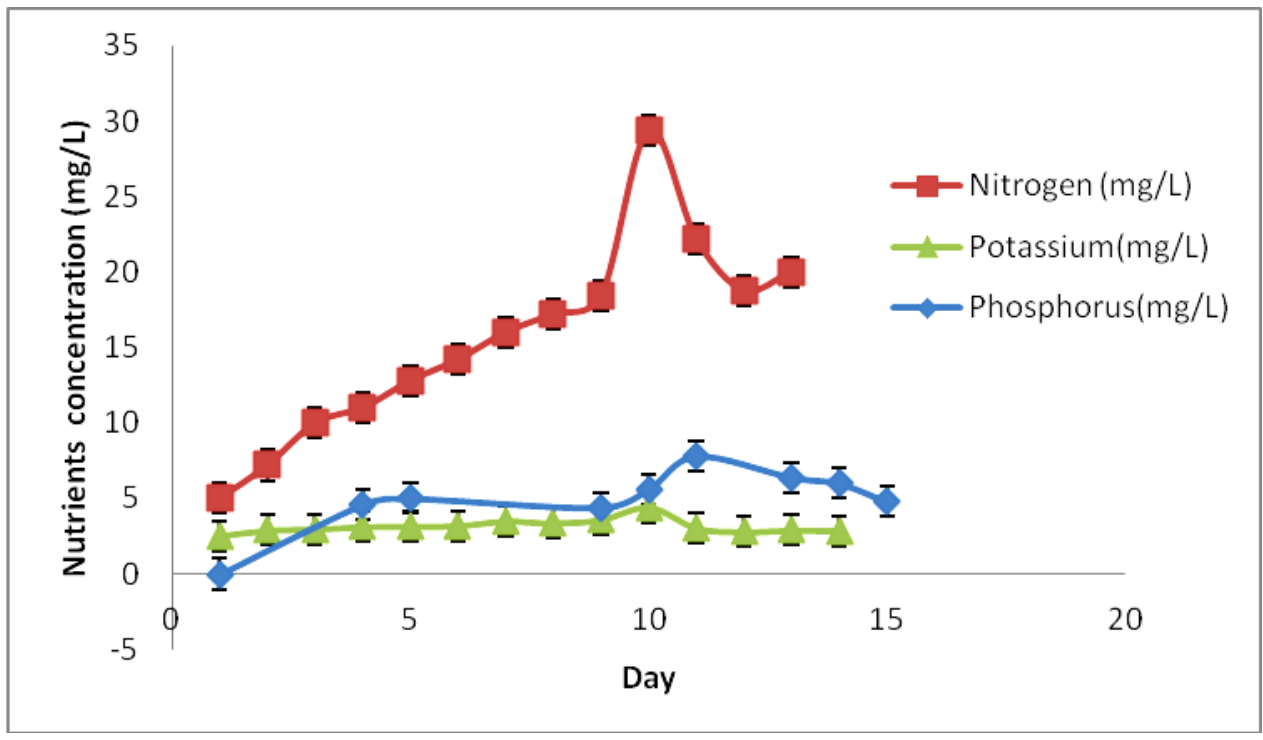

Fig. 1. Nutrients profile (N, P and K) in FS mixed with SA.

\subsection{Kinetic Parameters}

Kinetic study indicates the presence of high affinity transport systems for the uptake of N, P and $\mathrm{K}$ in the SA. N, P and K concentrations were fitted to Michaelis-Menten equation. The experimental data were plotted using Lineweaver -Bulk plot with the aid of Excel software showing $r^{2}$ more than 0.8 as shown in Figure 2, 3 and 4. Based on Figure 2, the value of Vmax obtained for $\mathrm{N}$ was $6.28 \mathrm{mg} / \mathrm{l}$.d and the $\mathrm{Km}$ was $82.17 \mathrm{mg} / \mathrm{l}$. For $\mathrm{K}$, the Vmax and $\mathrm{Km}$ value obtained from the Figure 3 were $0.07 \mathrm{mg} / \mathrm{l} . \mathrm{d}$ and $4.55 \mathrm{mg} / \mathrm{l}$ respectively while for $\mathrm{P}$, based on the Figure 4 the Vmax obtained was $9.80 \mathrm{mg} / \mathrm{l} . \mathrm{d}$ and $\mathrm{Km}$ was $60.96 \mathrm{mg} / \mathrm{l}$. The 
kinetic data for the nutrients uptake for this study was summarized in Table 1. The Km represented the binding affinity between the AMF and the nutrients while Vmax determined the maximum nutrients uptake by AMF. From the results, it shows that $\mathrm{K}$ has the lowest value of $\mathrm{Km}$ (highest affinity) followed by $\mathrm{P}$ and N. P and K were both the micronutrients that immobilize in the soil, therefore the binding between the $\mathrm{K}$ and AMF was stronger compared to N. From the observation of the macronutrients (N, P and $\mathrm{K}$ ) uptake, it shows that the Vmax of the $\mathrm{P}$ uptake by AMF was the highest compared to $\mathrm{N}$ and $\mathrm{K}$. This is because the higher $\mathrm{P}$ acquisition by mycorrhizal plants was generally attributed to production of large amounts of alkaline and acid phosphates by AMF during the course of infection that help the host plant in $\mathrm{P}$ absorption, existence of surface $\mathrm{P}$ on AMF that enable them to obtain soil $\mathrm{P}$ more readily than non-mycorrhizal roots [12]. This proved the ability of AMF to encourage absorption or uptake of $\mathrm{P}$ in the soil as earlier reported by Smith and Read [3] which stated that AMF is very effective in helping the plants to absorb $\mathrm{P}$ from the soil and invariably prevents $\mathrm{P}$ runoff that leads to eutrophication (undesired biological growth and productivity).

The increment of $\mathrm{P}$ uptake by AMF was well documented and considered as one of the reasons for the enhancement of the host plant growth under various soil conditions. The benefit of the mycorrhizal effect even in the soils with high levels of $\mathrm{P}$ provided evidence that AMF contributed efficiently to $\mathrm{P}$ absorption and its transportation in the plant. The increase in the $\mathrm{P}$ capacity of the plants can be attributed to the large increase in soil exploration area (more than one hundred times) due to mycorrhizal external mycelium production, its greater efficiency of nutrient absorption and higher affinity (lower $\mathrm{Km}$ ) for $\mathrm{P}$ uptake from the soil solution. More recent work demonstrated that $\mathrm{C}$ also acts as a trigger for fungal $\mathrm{N}$ and $\mathrm{K}$ uptake and transport [11]. $\mathrm{N}$ in the soil had high mobility to move to plant roots through mass flow, therefore it had been suggested that the AMF played little role in N uptake. Matsumura et al., [13] George et al. [14] and Hajiboland et al. [15] also suggested that $\mathrm{N}$ uptake by AMF itself was usually low compared to the total demand by plants. N, P and K were important elements in the soil, however only small amount of $\mathrm{K}$ and $\mathrm{N}$ being uptake by AMF compared to $\mathrm{P}$. This is because the uptake of the nutrients dependent on the type of host plant needs. From this case, it can be assumed that, $\mathrm{P}$ was more important to the onions, therefore the P uptake by the AMF was the highest.

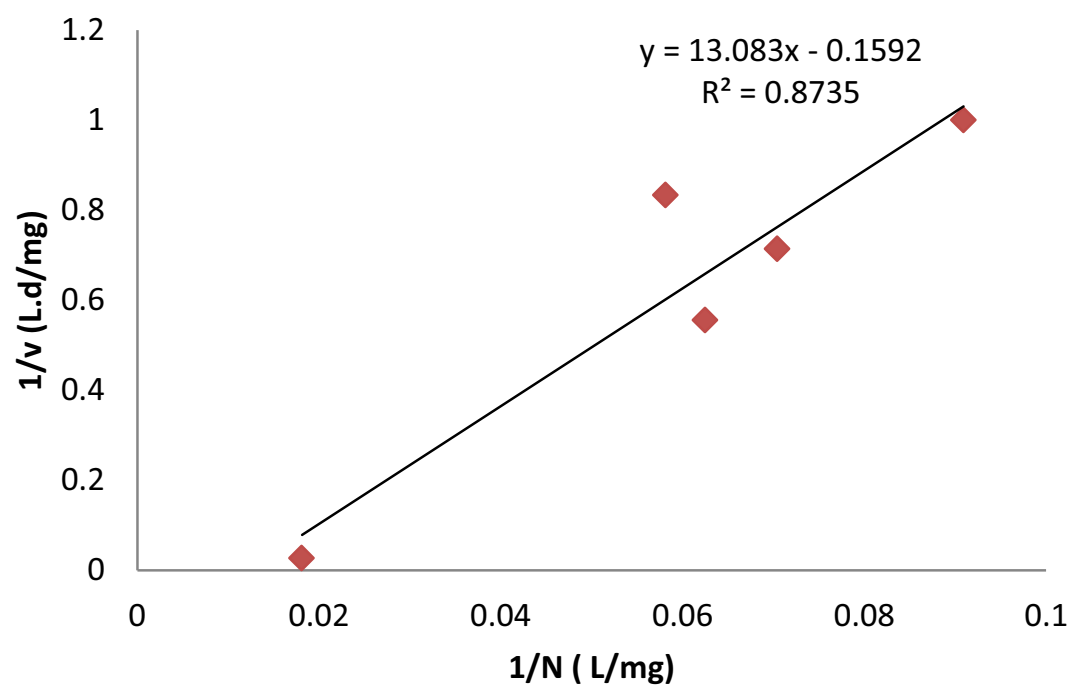

Fig. 2. Nitrogen (N) uptakes by AMF. 


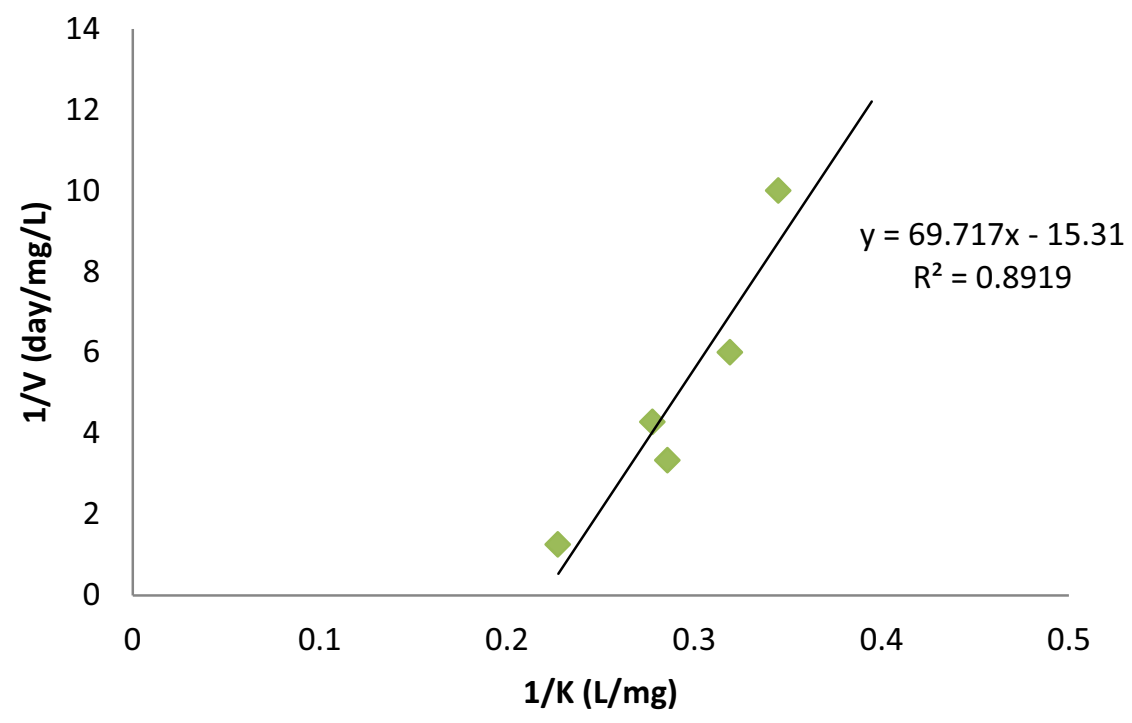

Fig. 3. Potassium (K) uptakes by AMF.

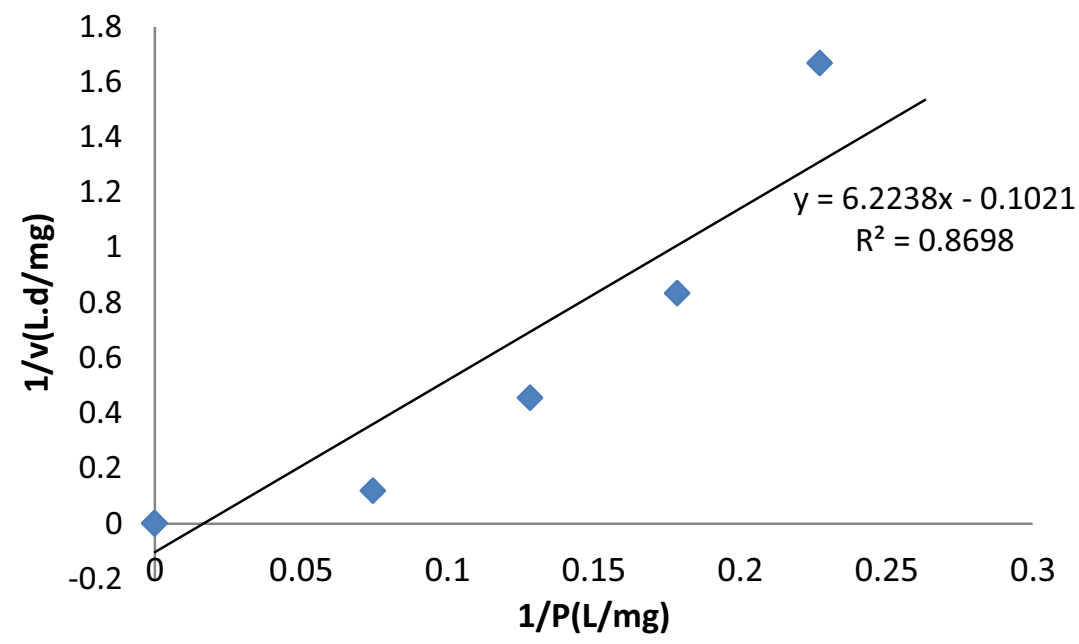

Fig. 4. Phosphorus (P) uptakes by AMF.

Table 1. Kinetic data for nutrient uptake.

\begin{tabular}{|l|c|c|c|c|}
\hline \multirow{2}{*}{ Elements } & \multicolumn{2}{|c|}{ Vmax (mg/l.d) } & \multicolumn{2}{c|}{ Km (mg/l) } \\
\cline { 2 - 5 } & $\begin{array}{c}\text { This } \\
\text { study }\end{array}$ & $\begin{array}{c}\text { Other researcher } \\
{[\mathbf{1 6 , 1 7 ]}}\end{array}$ & $\begin{array}{c}\text { This } \\
\text { study }\end{array}$ & $\begin{array}{c}\text { Other researcher } \\
{[\mathbf{1 6 , 1 7 ]}}\end{array}$ \\
\hline Nitrogen & 6.28 & 2.28 & 82.17 & 61.27 \\
\hline Potassium & 0.07 & 0.83 & 4.55 & 7.91 \\
\hline Phosphorus & 9.80 & 3.6 & 60.96 & 37.92 \\
\hline
\end{tabular}


The kinetic parameters of nutrients uptake by AMF from other researcher also been summarized in Table 1. From the result, it shows that the $\mathrm{Km}$ and Vmax values obtained for the $\mathrm{N}$ and $\mathrm{P}$ from this study were higher compared to the others. This was because the host plant (onion plant) required a high level of nutrients in the soil compared to other host plant. However, the Vmax and $\mathrm{Km}$ obtained for $\mathrm{K}$ was lower compared to others because the $\mathrm{K}$ needed by the host plant was just in small amount.

\section{Conclusions}

Kinetic study showed $\mathrm{P}$ has the highest maximum nutrient uptake by AMF compared to $\mathrm{N}$ and $\mathrm{K}$. The values of $\mathrm{Vmax}$ and $\mathrm{Km}$ obtained for $\mathrm{P}$ was $9.80 \mathrm{mg} / \mathrm{l} . \mathrm{d}$ and $60.96 \mathrm{mg} / \mathrm{l}$ respectively which were slightly higher compared to other researcher. This was because the host plant required high $\mathrm{P}$ nutrients than usual. Result from this study proved that application of soil containing AMF (SA) increased nutrient (N, P and K) concentrations in the flooded soil. From a practical point of view, SA can be a valuable option for farmers to improve the sustainability of agro ecosystem by reducing the use of chemical fertilizer that gives environmental problem.

\section{References}

1. S.F. Bender, M.G. Heijden, J. Appl. Ecol., 52, 228 (2014)

2. E.V. Feldman, Student Pulse, 7, 9 (2015)

3. S.E. Smith, D. J. Read, Mycorrhizal Symbiosis, (Third Edition. Academic Press, London, 2008)

4. M. Ayesu, G. Gyabaah, J. Ecol., 4, 299 (2014)

5. F. Ardestani, Int. J. Energy Environ., 2, 117 (2011)

6. A. Jessen, Plant Soil, 70, 155 (1983)

7. S.F. Wright, A. Upadhyaya, Soil Sci., 161, 575, 1998

8. M.C. Rillig, P.D. Steinberg, Soil Biol. Biochem., 34, 1371 (2002)

9. G.W.T. Wilson, C.W Rice, M.C. Rillig, A. Springer, D.C. Hartnett, J. Ecol., 12, 452 (2009)

10. B. Jeff, Mind your P's and K's in Soils and crops, (The Samuel Roberts Noble Foundation, Inc. 2011)

11. C.R. Fellbaum, E.W. Gachomo, Y. Beesetty, S. Choudhari, G.D. Strahan, P.E. Pfeffer, K. Toby, B. Heike, Plant Signal Behav., 7 (11), 1509 (2012)

12. G.R. Venkateshwar, C. Manoharacharyl, B.R. Rajeswara, Journal of Science, 131, 47 (2011)

13. A. Matsumura, S. Taniguchi, K. Yamawaki, R. Hattori, A. Tarui, K. Yano, H. Daimon, Am. J. Plant Sci., 4, 2290 (2013)

14. E. George, H. Marschner, I. Jakobson, Crit. Rev. Biotechnol., 15, 257 (1995)

15. R. Hajiboland, N. Aliasgharzad, R. Barzeghar, Plant Soil Environ., 55, 93 (2009)

16. T.J. Albaugh, H.L. Allen, T.R. Fox, Tree Physiology, 28, 1083 (2008)

17. P.M. Bradley, J. Ecol., 71, 282 (1990) 